\title{
Reduction and reallocation of water use of products in Beijing
}

\author{
Xu Zhao ${ }^{1,2}$, Martin Tillotson ${ }^{3}$, Zhifeng Yang ${ }^{1 *}$, Hong Yang ${ }^{4}$, Junguo Liu ${ }^{2}$ \\ ${ }^{1}$ State Key Laboratory of Water Environment Simulation, School of Environment, Beijing Normal University, \\ Beijing 100875, China; \\ ${ }^{2}$ School of Nature Conservation, Beijing Forestry University, Beijing 10083, China; \\ ${ }^{3}$ water@ leeds, School of Civil Engineering, University of Leeds, Leeds LS2 9JT, United Kingdom \\ ${ }^{4}$ Swiss Federal Institute of Aquatic Science and Technology, Ueberlandstrasse 133, 8600 Duebendorf, Switzerland \\ *corresponding author at: State Key Laboratory of Water Environment Simulation, School of Environment, \\ Beijing Normal University. No.19 Xinjiekouwai Street, Beijing 100875, China. Tel./Fax.: 86 (10) 58807951; \\ E-mail: zfyang@bnu.edu.cn (Z.Yang),xu.zhao.water@hotmail.com (X. Zhao).
}


Abstract: The virtual water concept has received significant attention through manifesting the role of human activities such as consumption and international trade on water resources. However, few studies have focused on how the interactions of local supply chain exert impact on local water resources associated with virtual water flows. In this study, we introduce an indicator which is attached to the virtual water concept, termed the "internal water use of products" (IWUP), to examine the direct and indirect water use from local water supply for goods and services in Beijing for the years 1997, 2000, 2002, 2007, and 2010. This indicator links the pressure on local water resources to the final products with sectoral details, highlighting the importance of economic analysis in local water resource management. A structural decomposition analysis revealed that the increase in economic water productivity would have caused Beijing's IWUP to decrease by 196\% from 1997 to 2010, if other determining factors remained constant. Such great efficiency improvements have allowed Beijing to fulfill its objectives of economic growth, whilst in the meantime reducing the water used in production. However, we also found that production structure adjustment would increase the IWUP, mainly due to a shift from agricultural and industrial sectors to service sectors.

Key words: internal water use of products, virtual water, input-output analysis, structural decomposition analysis 


\section{Introduction}

The imbalance of water supply and increasing water demand has become a serious problem for many local authorities (Llop, 2013; Zhao et al., 2015). It is widely known that most local water supply is used for the production of goods and services. However, less attention is given to the fact that this water is then embodied in goods and services to their places of consumption, which may be across local, regional and international boundaries. Such water flows along the economic supply chain from on-site (direct) water use to final products are not real water flows but virtual water flows. Introduced by Allan (Allan, 1992), the virtual water concept has since developed into two research areas, i.e. virtual water trade and water footprint. Virtual water trade studies focus on how water demand in one location can lead to freshwater depletion in other locations through trade (Yang et al., 2013a). Whilst, as a consumption-based indicator, water footprint is used to quantify the water use derived from consumption of final products (Feng et al., 2011; Hoekstra and Chapagain, 2006). Both indicators appreciate the importance of extending the water study to global dimensions (Hoekstra and Mekonnen, 2012). However, few studies have focused on how the interactions of the local supply chain exert impact on local water resources associated with virtual water flows.

The effects of the supply chain can indirectly determine changes in water use. For example, it is a direct effect that expanded production in upstream sectors increases onsite water use, and such expansion might be driven by increasing need for raw materials 
from local downstream industries. The above driving force can be attributed to indirect effects arising from supply chain interactions (Zhang, 2010). Policy makers usually acquire the information of direct effects. For example, in China water statistics provide the direct water use in each productive sector (defined hereafter as direct water use of products, DWUP). However, quantifying the changes in indirect effects, which are often ignored, can answer a series of questions relating to local economic and water management, such as how production structure adjustment can affect local water use, or what are the key sectors that drive the direct and indirect water use through the supply chain.

This paper aims to propose a framework to study the drivers of local water use changes derived from the interactions of the local economic system. First, we introduce a virtual water related indicator called the internal water use of products (IWUP). IWUP is defined as the water required to support local production of final products. 'Internal' means that no imported products are considered in the process. Both water footprint and IWUP underline the supply chain effects, but they have different scopes. The starting point of the water footprint is to highlight the consumption impact of a region to water resources wherever the production happens. Such impact is usually beyond a region's territorial boundary through importing products. Whereas IWUP in turn traces how the water resources of a region are influenced by final consumption and local supply chain effects, thus providing information of interrelationships between water use and local economy. 
Second, we carry out a decomposition analysis to study the driving forces of changes in IWUP. There are two commonly used decomposition techniques: index decomposition analysis (IDA) and structural decomposition analysis (SDA) (Su and Ang, 2012). Detailed comparison of the two methods can be found in Hoekstra and van den Bergh (2003), and Su and Ang (2012). In short, IDA decomposes the resource use or emission without sector information, while SDA is associated with the input-output methodology incorporating the supply chain effects with detailed sector information. In this study, we use SDA with a single-region input-output (SRIO) analysis to quantify the drivers of IWUP changes. The SDA model has been widely employed to study the key drivers of energy use and carbon dioxide $\left(\mathrm{CO}_{2}\right)$ emissions (Guan et al., 2008; O'Mahony et al., 2012; Wood, 2009), but has rarely been used for water, with a few notable exceptions for studies of water footprints (Guan et al., 2014; Zhang et al., 2012). The rationale of selecting the SRIO methodology and the comparison with other inputoutput techniques are presented in the Methodology section.

The mega-city of Beijing was chosen for a case study with the years 1997, 2000, 2002, 2007, and 2010. The provision of sufficient water is becoming a great challenge for the world's large cities (Darrel Jenerette and Larsen, 2006). By 2050, 1 out of 3 billion of the world's urban dwellers are expected to live in cities with perennial water shortage (McDonald et al., 2011). Beijing, a mega-city of about 20 million inhabitants, is facing severe water shortage due to its rising population and poor freshwater availability. The data for 2010 shows that water availability for Beijing was only 140 
$\mathrm{m}^{3} /$ capita (Beijing Water Resources Bureau, 1988-2012), much lower than the acknowledged water scarcity threshold of $1700 \mathrm{~m}^{3} /$ capita (Falkenmark and Widstrand, 1992). Since the late 1990s the city has suffered from ongoing drought, whilst during the period from 1997 to 2010, the population of Beijing has increased by $61 \%$ and the real gross domestic product (GDP) has increased more than fourfold (Beijing Municipal Bureau of Statistics, 1989-2013).

Several studies have shown water use increases in mega-cities, mainly due to population growth and industrial development (Darrel Jenerette and Larsen, 2006; Jury and Vaux, 2005). However, on-site water use for producing goods and services in Beijing has seen a declining trend. Between 1988 and 2010 the water use for agricultural and industrial production in Beijing decreased by $48 \%$ and $64 \%$ respectively (Beijing Water Resources Bureau, 1988-2012), and the declining trend has continued since then. Hence, it is interesting to examine the economic explanations for such a large decrease in water use against substantial economic growth.

\section{Methodology and data}

\subsection{Conceptual framework of water reallocation in the supply chain of products}

In examining the factors contributing to changes in IWUP, we examined the total volume of freshwater used in all steps of the production supply chain. In particular, such accounting highlights the role of downstream industries on water demand. Such a 
role is also part of the extended producer responsibility, which refers to: "Producers of products should bear a significant degree of responsibility not only for the environmental impacts of their products downstream from the treatment and disposal of their products, but also for their upstream activities inherent in the selection of materials and in the design of products" (Lenzen et al., 2007).

In order to illustrate the above process we use a simple flow diagram of water reallocation in the supply chain of products (Fig. 1). Here, we assume there are only two sectors (Food and Food Processing) in a hypothetical region, and the Food sector produces wheat and maize for onward sale or further processing. The Food Processing sector produces the processed products using wheat and maize as raw materials. Here the water embodied in the imported products, which is also referred to as virtual water import (Hoekstra et al., 2011), is not considered in the process. Since we want to trace the virtual water flow from local water supply in the supply chain.

Fig. 1 shows that the total DWUP is $130 \mathrm{~m}^{3}$, and the DWUP for the Food sector is $100 \mathrm{~m}^{3}$ (60 $\mathrm{m}^{3}$ for wheat and $40 \mathrm{~m}^{3}$ for maize). However, as $60 \mathrm{~m}^{3}$ of water (embodied in the food products as raw materials) flows into Food Processing, the water use in producing the food products for final demand, i.e. the IWUP is actually only $40 \mathrm{~m}^{3}$ and the IWUP of Food Processing is $90 \mathrm{~m}^{3}$ (its DWUP is $30 \mathrm{~m}^{3}$ ). Hence, IWUP represents a real pressure on local water resources caused by local production activities. Meanwhile, it shows how the local water supply was reallocated among the supply 
chain to different sectors. Such a reallocation extends the producer responsibility for both direct and indirect water use.

\subsection{Top-down approaches in quantifying IWUP}

Top-down and bottom-up are two quantification approaches used in virtual water related studies (Yang et al., 2013a). The detailed comparison of the two approaches has been given by Yang et al. (2013a) and Feng et al. (2011). In a nutshell, a bottom-up method accounts for the water use for a single product with detailed descriptions of individual production processes. The top-down method usually refers to input-output analysis (IOA), which shows the interdependency among different economic sectors (Feng et al., 2011). An IOA has long been recognized as an appropriate tool to attribute resource use or pollution to final products in a consistent framework (Wiedmann, 2009).

In recent years, many studies have adopted SRIO to quantify water footprint and virtual water trade (Guan and Hubacek, 2007; Guan et al., 2014; Zhao et al., 2009). A major limitation of SRIO is the assumption that imported goods and services are being produced using the same technology as the domestic technology in the same sector (Wiedmann, 2009). SRIO can lead to errors in quantifying the virtual water embodied in the imported goods and services, i.e. virtual water import (external water footprint). A multi-region input-output model (MRIO) can overcome this limitation by distinguishing between local and foreign production technology, but it substantially increases the data requirement and computational complexity. 
Our study employed a SRIO to account for the IWUP. As IWUP doesn't contain the virtual water import, the above mentioned limitation of SRIO has no effect on the IWUP. Following the framework in Fig. 1, we present the formula of calculating IWUP associated with a SRIO. Local goods and services are consumed by two kinds of consumers (f): consumers in the local region, which represent internal final demand (i), and consumers in other regions, which represent export (e). So the IWUP can be expressed as:

$$
\operatorname{iwup}=\mathbf{d} \cdot \mathbf{L} \cdot \mathbf{f}=\mathbf{d} \cdot(\mathbf{I}-\mathbf{A})^{-1} \cdot(\mathbf{i}+\mathbf{e})
$$

Where iwup is the vector of IWUP, $\mathbf{d}$ is the vector of direct water use intensity, which is calculated as the per unit output of the direct water use of products (DWUP). The reciprocal of $\mathbf{d}$ is the economic water productivity. $\mathbf{L}=(\mathbf{I}-\mathbf{A})^{-1}$ is the Leontief inverse matrix. I represents the identity matrix and $\mathbf{A}$ represents the technical coefficient matrix that contains the inputs of each sector per unit of their output in monetary terms. $\mathbf{f}$ is the vector for total final demand, and can be divided into $\mathbf{i}$ and $\mathbf{e} . \mathbf{i}$ is the vector for internal final demand, indicating the local production that is used for local consumption, and $\mathbf{e}$ is the vector for exports.

\subsection{Structural decomposition method}

We used a structural decomposition analysis to study the driving forces that determine the change of IWUP. The approach changes the multiplicative factors into additive parts following Hoekstra and van den Bergh (2003). According to equation (1), 
we divided the change in IWUP into four driving forces: direct water use intensity (d), production structure adjustment $(\mathbf{L})$, internal final demand (i), and exports (e). Among the driving forces, $\mathbf{d}$ reflects the effects of technological improvements on water use efficiency. The Leontief inverse matrix $\mathbf{L}$ is a reflection of the economic production structure (De Haan, 2001; Guan et al., 2008). The change in IWUP from time 0 to time 1 can be decomposed into the selected driving forces using the following equations:

$$
\begin{aligned}
& \Delta \operatorname{iwup}=\operatorname{iwup}_{1}-\operatorname{iwup}_{0} \\
& =\left(d_{1} \cdot L_{1} \cdot f_{1}\right)-\left(d_{0} \cdot L_{0} \cdot f_{0}\right) \\
& =\Delta d \cdot w_{d}+\Delta L \cdot w_{1}+\Delta f \cdot w_{f}
\end{aligned}
$$

Where subscripts 0 and 1 represent the two points in time. $\mathbf{w}_{\mathrm{d}}, \mathbf{w}_{\mathrm{l}}$, and $\mathbf{w}_{\mathrm{f}}$ are weights to be solved for the direct water consumption intensity, the Leontief inverse matrix, and the total final demand, respectively. $\Delta \mathbf{d}=\mathbf{d}_{1}-\mathbf{d}_{\mathbf{0}}, \Delta \mathbf{L}=\mathbf{L}_{1}-\mathbf{L}_{\mathbf{0}}$, and $\Delta \mathbf{f}=\mathbf{f}_{1}-\mathbf{f}_{\mathbf{0}}$. One of the solutions to equation (2) can be shown as follows:

$$
\begin{aligned}
& \Delta \text { iwup }=\text { iwup }_{1}-\text { iwup }_{0} \\
& =\left(d_{1} \cdot L_{1} \cdot f_{1}\right)-\left(d_{0} \cdot L_{0} \cdot f_{0}\right) \\
& =\Delta d \cdot L_{1} \cdot f_{1}+d_{0} \cdot L_{1} \cdot f_{1}-d_{0} \cdot L_{0} \cdot f_{0} \\
& =\Delta d \cdot L_{1} \cdot f_{1}+d_{0} \cdot \Delta L \cdot f_{1}+d_{0} \cdot L_{0} \cdot f_{1}-d_{0} \cdot L_{0} \cdot f_{0} \\
& =\Delta d \cdot L_{1} \cdot f_{1}+d_{0} \cdot \Delta L \cdot f_{1}+d_{0} \cdot L_{0} \cdot \Delta f
\end{aligned}
$$

In equation (3), the solved weights are: $\mathbf{w}_{\mathbf{d}}=\mathbf{L}_{\mathbf{1}} \cdot \mathbf{f}_{\mathbf{1}}, \mathbf{w}_{\mathbf{l}}=\mathbf{d}_{0} \cdot \mathbf{f}_{\mathbf{1}}$, and $\mathbf{w}_{\mathbf{f}}=\mathbf{d}_{0} \cdot \mathbf{L}_{\mathbf{0}}$. However, such a solution is not unique. Different solutions can be obtained by simply changing the permutation of the three multiplied variables, i.e. d, L, and f. For $n$ multiplicative variables, there are $n$ ! solutions (Dietzenbacher and Los, 1998). In our case, there are $3 !=6$ solutions. Diezenbacher and Los (1998) solved the problem with a 'two polar' method by calculating the mean of all solutions. One attribute of the 'two 
polar' method is that each solution has a 'mirror image'. De Haan (2001) presented a sensitivity analysis to show that the 'mirror image' decomposition forms substantially diminish the percentage deviation from the average estimate. Due to its good performance, this method has been widely used in structural decomposition analysis (De Haan, 2001; Guan et al., 2008; Su and Ang, 2012). The solution in our case with the 'two polar' method is shown in Equations (4) to (7). It is worth mentioning that we further decomposed the final demand (f) into internal final demand (i) and exports (e) to emphasize the effects of exports.

$$
\Delta d \cdot w_{d}=\Delta d \cdot\left(1 / 3 L_{0} \cdot f_{0}+1 / 6 L_{0} \cdot f_{1}+1 / 6 L_{1} \cdot f_{0}+1 / 3 L_{1} \cdot f_{1}\right)
$$

$\Delta L \cdot W_{1}=\Delta L \cdot\left(1 / 3 d_{0} \cdot f_{0}+1 / 6 d_{0} \cdot f_{1}+1 / 6 d_{1} \cdot f_{0}+1 / 3 d_{1} \cdot f_{1}\right)$

$$
\Delta i \cdot w_{f}=\Delta i \cdot\left(1 / 3 d_{0} \cdot L_{0}+1 / 6 d_{0} \cdot L_{1}+1 / 6 d_{1} \cdot L_{0}+1 / 3 d_{1} \cdot L_{1}\right)
$$

$$
\Delta e \cdot W_{f}=\Delta e \cdot\left(1 / 3 d_{0} \cdot L_{0}+1 / 6 d_{0} \cdot L_{1}+1 / 6 d_{1} \cdot L_{0}+1 / 3 d_{1} \cdot L_{1}\right)
$$

\subsection{Data}

The SRIO table for China is officially compiled every five years, and the most upto-date one is from 2007 (IO table in 2012 is still in compilation). Since the input-output (IO) table and water use data before 1997 is unreliable, our study chose the IO tables in years 1997, 2002, and 2007, and an extended table in 2000 and 2010, which were derived from the IO tables in 1997 and 2007 respectively. 14 sectors were grouped according to the IO table for Beijing and available sectoral water use data. These were 
(1) Agriculture, (2) Mining, (3) Food and tobacco processing, (4) Textile, leather, and other fiber products, (5) Lumbering and paper products, (6) Petroleum processing and coking, (7) Chemicals, (8) Non-metal mineral products, (9) Metal products, (10) Machinery and equipment, (11) Electricity, gas, and water production and supply, (12) Construction, (13) Wholesale and retail trade and passenger transport, and (14) Other services. Among these, sectors (2) to (12) are defined as Industrial sectors, and sectors (13) to (14) are Service sectors.

In this study, local water supply is defined as water abstracted locally or transferred from outside the regional boundary into the local water supply system. Water use is defined as the gross quantity of water distributed to users, including water lost in distribution, such as through leakage. The water use data of the Agriculture, Industry and Service sectors is taken from the Beijing Water Resources Bulletin (Beijing Water Resources Bureau, 1988-2012). The breakdown of water use to Industrial sectors is derived from the Beijing Economic Census Yearbook (Beijing Municipal Statistics Bureau, 2004). The breakdown of water use to Service sectors is taken from Zhao et al.(2010). The water supply of Beijing comes from surface water, ground water, transferred water, and recycled water. Recycled water including reused rainfall and sewage water is an important source of Beijing's water supply (Wu and Chau, 2006), accounting for 14\% of total water supply in 2010. 


\section{Results}

\subsection{Direct water use of products}

DWUP represents the water used directly by each sector. It can be seen in Table 1 that DWUP is unevenly distributed amongst the 14 sectors. Agriculture uses most of the DWUP, accounting for $47.2 \%$ based on the average for the five years considered. This is followed by Electricity, gas, and water production and supply (19.2\%), and Wholesale, retail trade and passenger transport (19.6\%). Combined, these three sectors used an average of $86 \%$ of the total DWUP based on the five years of available data.

The total DWUP decreased by $21 \%$ from 1997 to 2010 . The main contributor to the decline in total DWUP was agriculture, accounting for 52\% (from 1812 million $\mathrm{m}^{3}$ to 1140 million $\mathrm{m}^{3}$ ) of the sectors with decreased DWUP between 1997 and 2010. The decrease is largely due to the decline of agricultural production in Beijing, especially grain production. The production volume of major grain crops decreased from 2.37 million tons in 1997 to 1.16 million tons in 2010, and available arable land decreased by $32 \%$. The share of agriculture in total GDP decreased from $3.7 \%$ to $0.9 \%$ between 1997 and 2010 (Beijing Municipal Bureau of Statistics, 1989-2013). Another contributor to the total DWUP decrease is Electricity, gas, and water production and supply. About $46 \%$ of the decrease was attributed to this sector (from 863 million $\mathrm{m}^{3}$ to 276 million $\mathrm{m}^{3}$ ) between 1997 and 2010. This is partly attributed to Beijing's effort to improve water use efficiency for electricity production since 2002. For example, it 
has changed its thermal power plants from once-through cooling systems to open cycle cooling systems (Du, 2006). Despite the downward trend for total DWUP, the DWUP of the two service sectors increased by $77 \%$ from 1997 to 2010 . The increase is mainly due to Beijing's rapid urban development during the period (Yang et al., 2013b).

\subsection{Internal water use of products}

DWUP turns into an identical volume of virtual water after being 'embodied' in the supply chain of products. This virtual water is reallocated to different sectors and finally flows to consumers as IWUP. The process is shown as a matrix in Table 2 for the situation in 2010. Each column of the matrix demonstrates how the DWUP of a sector is reallocated to all sectors in a virtual form. While each row of the matrix shows how much virtual water is needed from all sectors to fulfill the final demand of consumers of a sector. As a result, the total IWUP is equal to the total DWUP, but they differ at the sectoral level (see Table 1 and Table 2).

The IWUP of each sector shows the extent of pressure on local water resources derived from the final products of that sector. Based on the five years' average, the top five sectors of IWUP are |Agriculture (29\%); Other services (25\%); Wholesale, retail trade and passenger transport (13\%); Food and tobacco processing (12\%); and Construction (6.5\%). It was also found that there are sectors with IWUP significantly larger than their DWUP, namely: Food and tobacco processing, Machinery and equipment; Construction; and Textile, leather, and other fiber products. These sectors 
are characterized by being 'downstream' of the supply chain, and require a large amount of indirect water from 'upstream' activities. Traditionally, these sectors are considered to be less water intensive. However, by considering both direct and indirect water needs in the sector, they become much more water intensive. For example, in 2010 the DWUP of Food and tobacco processing was only 31.1 million $\mathrm{m}^{3}$, but the IWUP of this sector was 172.5 million $\mathrm{m}^{3}$, nearly 5.5 times of its DWUP.

Our analysis showed that eight of the sectors under study decreased their IWUP between 1997 and 2010; the rate of reduction ranging from 27\%-91\%. Amongst these, $56 \%$ of the total decrease came from Agriculture (23\%) and Food and tobacco processing (33\%). This is explained by the large drop in DWUP for the Agriculture sector. Four sectors increased their IWUP and, amongst these, the two service sectors contributed $88 \%$ to the increase.

\subsection{Decomposition analysis of internal water use of products}

The structural decomposition analysis for 1997, 2000, 2002, 2007, and 2010 showed the significant contribution of increasing economic water productivity in decreasing the total IWUP, despite the offset effects caused by the change in the three other determining factors (i.e. production structure adjustment, internal final demand, and exports) (Fig. 2). The improvement of economic water productivity would have caused Beijing's IWUP to decrease by 6987 million $\mathrm{m}^{3}$ (196\%) during the study period if other determining factors had remained constant. These great efficiency 
improvements has allowed Beijing to further develop its economy without increasing its water use in the production of goods and services. Consequently, Beijing has expanded its economic output for both internal final demand and export. For internal final demand, the change would have increased the total IWUP by $66 \%$ above the 1997 level, if other determining factors remained constant. The increased export of goods and services in the period led to an $85 \%$ increase in total IWUP.

It is generally believed that Beijing has significantly reduced its water use due to production structure adjustments through developing service sectors (Yang et al., 2013b). From 1997 to 2010, the share of agriculture in total GDP decreased from 3.7\% to $0.9 \%$, while the share of industry decreased from $37.6 \%$ to $24 \%$ (Beijing Municipal Bureau of Statistics, 1989-2013). The changes have resulted in the service sectors dominating GDP with a share of 75.1\% in 2007, compared with 58.7\% in 1997 (Beijing Municipal Bureau of Statistics, 1989-2013). However, the results of our analysis show that with other determining factors remaining constant, the production structure adjustment would have caused the IWUP to increase by $24 \%\left(842\right.$ million $\mathrm{m}^{3}$ ) between 1997 to 2010. Since the service sectors are water intensive in terms of IWUP, the production structure adjustment to more service-based activities leads to more IWUP.

\section{Discussion}

Traditionally, environmental impacts are allocated to their immediate producers (Lenzen et al., 2007). Using IWUP as an indicator, our results highlight the water use 
in final products derived from local water supply. This on the one hand helps address the extended producer responsibility, and on the other hand shows the pressure on local water resources caused by final products. The pressure can be further broken down to sectors, showing the pulling effects of final products with sector details.

The driving forces of the downward trend in IWUP were analyzed with a structural decomposition analysis. Our results showed that technical improvements have significantly reduced water use in Beijing, causing reductions in both the total DWUP and IWUP. However we also found that production structure adjustment, in itself, has increased the IWUP. One production structure adjustment in Beijing is the shift from agricultural and industrial based activity to service based activity. The service sectors in Beijing have greatly expanded since 1995 (Yang et al., 2013b). The latest economic plans for Beijing have continued to call for the expansion of the service sector. For example, the 'Outline of the Eleventh Five-Year Plan of Beijing' (2006-2010) urged to "speed up the development of modern services" (Beijing Municipal Government, 2005), while the 'Outline of the Twelfth Five-Year Plan of Beijing' (2011-2015) emphasizes the need to "make the service sector big" (Beijing Municipal Government, 2011). However, what is often neglected is that service sectors will drive manufacturing output indirectly through the input of intermediate products from other water intensive industries (Suh, 2006), hence increasing indirect water use. In our case, the service sectors would have resulted in a 12\% increase in IWUP from 1997 to 2010, assuming the IWUP of the other sectors remained constant. So the development of the service 
sector should be undertaken more carefully, considering the full effect on local upstream sectors, which may be water intensive.

Our results show that the IWUP of Beijing decreased between 1997 and 2010. However, several studies have reported an increase in Beijing's water footprint based on SRIO analysis in recent years (Wang et al., 2013; Zhang et al., 2011). The main reason for the difference is that the IWUP has a different perspective compared with the water footprint. First, the IWUP incorporates the water 'embodied' in internal final demand and export, thus reflecting the local water use reallocation to final products among different economic sectors. Zhang et al. (2012) and Wang et al. (2013) calculated the water footprint from a consumption perspective, which refers to the water 'embodied' in internal final demand and imports. Second, water footprint accounting utilising SRIO analysis has to assume that the imported products have the same production technology as the local products, while the IWUP is free from such an assumption. More importantly, although both the IWUP and water footprint address the supply chain effect, the IWUP is easier to incorporate into water management since it is directly related to local water use.

This study, nevertheless, contains several limitations. First, the study used an IOA to calculate the IWUP. The general limitations and assumptions rooted in the IOA also apply to the quantification of the IWUP, such as the assumptions of homogeneity (i.e. each sector produces a single product, and all output uses the same processes and technology), and linear production functions (Bicknell et al., 1998). Overcoming the 
limitations of these assumptions is beyond the scope of this study. In addition, the quantification with sectoral aggregation in this study may decrease the accuracy of the results (Baiocchi and Minx, 2010). Second, water use changes are not only determined by economic driving forces, but also the changes in water supply which can be linked to other factors, including climate change. For example, agricultural water use may be decreased during a drought year because of lack of water.

\section{Conclusions}

The virtual water concept has received extensive attention through manifesting the role of human activities such as consumption and international trade on water resources. In this study, a new indicator attached to the virtual water concept was introduced to show how local economic systems reallocate the on-site water use to final products through virtual water flows. A SDA was used to evaluate the economic determinants (technological improvements, production structure adjustments, internal final demand, and exports) that underlie the changes in the IWUP with sector details. Such an attempt highlights the importance of incorporating economic drivers into local water management. The results can support decision making in balancing the trade-offs between local economic development and water resource depletion. It should be mentioned that such decision making is a multi-criteria problem, and has to be made by incorporating other relevant criteria with the participation of stakeholders (Zhao et al., 2006). 


\section{Acknowledgment}

The work is supported by the National Science Foundation of China for Innovation

Research Group (No.51421065); National Natural Science Foundation of China (No.51439001, 41161140353, 51009005); The Natural Science Foundation of Beijing (8151002); and the Worldwide Universities Network (WUN).

\section{References}

Allan, T., 1992. Fortunately there are substitutes for water: otherwise our hydropolitical futures would be impossible Priorities for Water Resources Allocation and Management. ODA, Southampton, London, pp. 13-26.

Baiocchi, G., Minx, J.C., 2010. Understanding changes in the UK's $\mathrm{CO}_{2}$ emissions: A global perspective. Environ Sci Technol 44, 1177-1184.

Beijing Municipal Bureau of Statistics, 1989-2013. Beijing Statistical Yearbook. China Statistics Press.

Beijing Municipal Government, 2005. The Outline of the 11th Five-year-plan of Economy and Social Development of Beijing, in: Beijing Municipal Commission of Development and Reform (Ed.).

Beijing Municipal Government, 2011. The Outline of the 12th Five-year-plan of Economy and Social Development of Beijing, in: Beijing Municipal Commission of Development and Reform (Ed.), Beijing.

Beijing Municipal Statistics Bureau, 2004. Beijing Economic Census Yearbook. China Statistics Press.

Beijing Water Resources Bureau, 1988-2012. Beijing Water Resource Bulletin (in Chinese). China Water Power Press, Beijing.

Bicknell, K.B., Ball, R.J., Cullen, R., Bigsby, H.R., 1998. New methodology for the ecological footprint with an application to the New Zealand economy. Ecol Econ 27, 149-160.

Darrel Jenerette, G., Larsen, L., 2006. A global perspective on changing sustainable urban water supplies. Global Planet Change 50, 202-211.

De Haan, M., 2001. A structural decomposition analysis of pollution in the Netherlands. Econ Syst Res 13, 181-196.

Dietzenbacher, E., Los, B., 1998. Structural decomposition techniques: sense and sensitivity. Econ Syst Res 10, 307-324. 
Du, Y., 2006. Completion and implementation of 'water saving plans of electricity sector in Beijing' (in Chinese), Guangming Online. http://www.chinagb.net/policy/gdpolicy/20070319/14091.shtml

Falkenmark, M., Widstrand, C., 1992. Population and water resources: a delicate balance, Population Bulletin. Population Reference Bureau, Washington, DC.

Feng, K., Chapagain, A., Suh, S., Pfister, S., Hubacek, K., 2011. Comparison of bottomup and top-down approaches to calculating the water footprints of nations. Econ Syst Res 23, 371-385.

Guan, D., Hubacek, K., 2007. Assessment of regional trade and virtual water flows in China. Ecol Econ 61, 159-170.

Guan, D., Hubacek, K., Tillotson, M., Zhao, H., Liu, W., Liu, Z., Liang, S., 2014. Lifting China's water spell. Environ Sci Technol 48, 11048-11056.

Guan, D., Hubacek, K., Weber, C.L., Peters, G.P., Reiner, D.M., 2008. The drivers of Chinese $\mathrm{CO}_{2}$ emissions from 1980 to 2030. Glob Environ Change 18, 626-634.

Hoekstra, A.Y., Chapagain, A.K., 2006. Water footprints of nations: Water use by people as a function of their consumption pattern. Water Resour Manag 21, 35-48.

Hoekstra, A.Y., Chapagain, A.K., Aldaya, M.M., Mekonnen, M.M., 2011. The water footprint assessment manual: Setting the global standard. Earthscan.

Hoekstra, A.Y., Mekonnen, M.M., 2012. The water footprint of humanity. Proc Natl Acad Sci USA.

Hoekstra, R., van den Bergh, J.C.J.M., 2003. Comparing structural decomposition analysis and index. Energ Econ 25, 39-64.

Jury, W.A., Vaux, H., Jr., 2005. The role of science in solving the world's emerging water problems. Proc Natl Acad Sci USA 102, 15715-15720.

Lenzen, M., Murray, J., Sack, F., Wiedmann, T., 2007. Shared producer and consumer responsibility - Theory and practice. Ecol Econ 61, 27-42.

Llop, M., 2013. Water reallocation in the input-output model. Ecol Econ 86, 21-27.

McDonald, R.I., Green, P., Balk, D., Fekete, B.M., Revenga, C., Todd, M., Montgomery, M., 2011. Urban growth, climate change, and freshwater availability. Proc Natl Acad Sci USA 108, 6312-6317.

Su, B., Ang, B.W., 2012. Structural decomposition analysis applied to energy and emissions: Some methodological developments. Energ Econ 34, 177-188.

Suh, S., 2006. Are services better for climate change? Environ Sci Technol 40, 65556560 .

Wang, Z., Huang, K., Yang, S., Yu, Y., 2013. An input-output approach to evaluate the water footprint and virtual water trade of Beijing, China. J Clean Prod 42, 172-179. Wiedmann, T., 2009. A review of recent multi-region input-output models used for consumption-based emission and resource accounting. Ecol Econ 69, 211-222.

Wu, C., Chau, K., 2006. Mathematical model of water quality rehabilitation with rainwater utilisation: a case study at Haigang. Int J Environ Pollut 28, 534-545. 
Yang, H., Pfister, S., Bhaduri, A., 2013a. Accounting for a scarce resource: virtual water and water footprint in the global water system. Curr Opin Sust 5, 599-606.

Yang, Z., Cai, J., Ottens, H.F.L., Sliuzas, R., 2013b. Beijing. Cities 31, 491-506.

Zhang, Y., 2010. Supply-side structural effect on carbon emissions in China. Energ Econ 32, 186-193.

Zhang, Z., Shi, M., Yang, H., 2012. Understanding Beijing's water challenge: a decomposition analysis of changes in Beijing's water footprint between 1997 and 2007. Environ Sci Technol 46, 12373-12380.

Zhang, Z., Yang, H., Shi, M., 2011. Analyses of water footprint of Beijing in an interregional input-output framework. Ecol Econ 70, 2494-2502.

Zhao, M.Y., Cheng, C.T., Chau, K.W., Li, G., 2006. Multiple criteria data envelopment analysis for full ranking units associated to environment impact assessment. Int $\mathbf{J}$ Environ Pollut 28, 448-464.

Zhao, X., Chen, B., Yang, Z.F., 2009. National water footprint in an input-output framework- a case study of China 2002. Ecol Model 220, 245-253.

Zhao, X., Liu, J., Liu, Q., Tillotson, M.R., Guan, D., Hubacek, K., 2015. Physical and virtual water transfers for regional water stress alleviation in China. Proc Natl Acad Sci USA 112, 1031-1035.

Zhao, X., Yang, H., Yang, Z., Chen, B., Qin, Y., 2010. Applying the input-output method to account for water footprint and virtual water trade in the Haihe River Basin in China. Environ Sci Technol 44, 9150-9156. 
Table 1 Direct water use of products (DWUP) VS. Internal water use of products (IWUP). Unit: million $\mathbf{~ m}^{3}$

\begin{tabular}{|c|c|c|c|c|c|c|c|c|c|c|}
\hline & \multicolumn{2}{|c|}{1997} & \multicolumn{2}{|c|}{2000} & \multicolumn{2}{|c|}{2002} & \multicolumn{2}{|c|}{2007} & \multicolumn{2}{|c|}{2010} \\
\hline & DWUP & IWUP & DWUP & IWUP & DWUP & IWUP & DWUP & IWUP & DWUP & IWUP \\
\hline Sec1:Agriculture & 1812 & 1071.4 & 1649 & 924.5 & 1545 & 1207.3 & 1244 & 523 & 1140 & 781.7 \\
\hline Sec2:Mining & 6 & 3.2 & 5.7 & 1.7 & 4.1 & 1.8 & 3.1 & 3.1 & 6.5 & 29.5 \\
\hline Sec3:Food and tobacco processing & 26.7 & 580.6 & 25.5 & 522.6 & 18.3 & 220.4 & 13.9 & 331.6 & 31.1 & 172.5 \\
\hline Sec4:Textile, leather, and other fiber products & 10.9 & 118.5 & 10.5 & 65.7 & 7.5 & 40 & 5.7 & 18.3 & 5.9 & 12.5 \\
\hline Sec5:Lumbering and paper products & 10.4 & 17.9 & 10 & 21.4 & 7.2 & 10.2 & 5.5 & 6.4 & 9.2 & 5.5 \\
\hline Sec6:Petroleum processing and coking & 6.6 & 1.8 & 6.3 & 3.3 & 4.5 & 14.2 & 3.5 & 13.4 & 12.7 & 15.2 \\
\hline Sec7:Chemicals & 29.9 & 43.4 & 28.6 & 31.6 & 20.5 & 104.9 & 15.7 & 66.5 & 38.1 & 55.5 \\
\hline Sec8:Non-metal mineral products & 29.8 & 21.3 & 28.5 & 20.4 & 20.5 & 4.2 & 15.6 & 10 & 15.5 & 7.9 \\
\hline Sec9:Metal products & 71.7 & 39.8 & 68.5 & 16.7 & 49.1 & 33.7 & 37.5 & 18.9 & 63.5 & 19.1 \\
\hline Sec10:Machinery and equipment & 44.5 & 165.0 & 42.6 & 118.6 & 30.5 & 140.4 & 23.3 & 128.2 & 51.4 & 169.4 \\
\hline Sec11:Electricity, gas, and water production and supply & 863.4 & 352.1 & 825.7 & 236.9 & 591.8 & 63.5 & 451.3 & 71 & 276.1 & 33.4 \\
\hline Sec12:Construction & 14.1 & 228.1 & 18 & 267.4 & 13.8 & 203.4 & 22.1 & 167.9 & 25.1 & 155.6 \\
\hline Sec13: Wholesale, retail trade and passenger transport & 466 & 282.9 & 594.3 & 385.2 & 455 & 346.4 & 726.7 & 515.2 & 826.7 & 441.8 \\
\hline Sec14:Other services & 168.1 & 634.3 & 214.4 & 911.8 & 164.2 & 541.4 & 262.2 & 956.6 & 298.2 & 900.4 \\
\hline Total volume & 3560.3 & 3560.3 & 3527.7 & 3527.7 & 2932 & 2932 & 2830 & 2830 & 2800 & 2800 \\
\hline
\end{tabular}


Table 2 Water reallocation from DWUP to IWUP among sectors (Each column demonstrates how the DWUP of a sector is reallocated to all sectors in a virtual form. Each row shows how much virtual water is need from all sectors to fulfill the final demand of consumers of a sector) Unit: million $\mathbf{m}^{3}$

\begin{tabular}{|c|c|c|c|c|c|c|c|c|c|c|c|c|c|c|c|}
\hline & Sec1 & Sec2 & Sec3 & Sec4 & Sec5 & Sec6 & Sec7 & Sec8 & Sec9 & Sec10 & Sec11 & Sec12 & Sec13 & Sec14 & IWUP \\
\hline Sec1 & 773.64 & 0.08 & 0.11 & 0.00 & 0.03 & 0.08 & 0.25 & 0.02 & 0.26 & 0.08 & 3.08 & 0.01 & 3.36 & 0.71 & 781.7 \\
\hline Sec2 & 1.49 & 3.87 & 0.03 & 0.02 & 0.10 & 0.47 & 0.22 & 0.05 & 0.48 & 0.23 & 11.49 & 0.02 & 10.11 & 0.91 & 29.5 \\
\hline Sec3 & 124.91 & 0.09 & 24.38 & 0.02 & 0.22 & 0.09 & 0.59 & 0.19 & 0.91 & 0.19 & 5.25 & 0.02 & 14.42 & 1.19 & 172.5 \\
\hline Sec4 & 2.68 & 0.01 & 0.01 & 4.85 & 0.04 & 0.02 & 0.13 & 0.01 & 0.07 & 0.04 & 0.92 & 0.01 & 3.51 & 0.24 & 12.5 \\
\hline Sec5 & 0.63 & 0.01 & 0.00 & 0.02 & 1.86 & 0.01 & 0.16 & 0.01 & 0.20 & 0.02 & 0.98 & 0.00 & 1.46 & 0.11 & 5.5 \\
\hline Sec6 & 0.55 & 0.09 & 0.01 & 0.00 & 0.02 & 6.88 & 0.08 & 0.01 & 0.09 & 0.05 & 1.51 & 0.01 & 5.62 & 0.28 & 15.2 \\
\hline Sec7 & 16.76 & 0.12 & 0.07 & 0.02 & 0.10 & 0.24 & 17.18 & 0.07 & 0.49 & 0.17 & 9.70 & 0.02 & 9.68 & 0.91 & 55.5 \\
\hline Sec8 & 0.34 & 0.05 & 0.01 & 0.00 & 0.02 & 0.02 & 0.11 & 3.77 & 0.12 & 0.04 & 1.33 & 0.00 & 1.94 & 0.15 & 7.9 \\
\hline Sec9 & 0.34 & 0.15 & 0.01 & 0.00 & 0.02 & 0.03 & 0.08 & 0.02 & 14.60 & 0.06 & 1.32 & 0.00 & 2.28 & 0.23 & 19.1 \\
\hline Sec10 & 11.13 & 0.31 & 0.18 & 0.16 & 0.52 & 0.42 & 3.28 & 0.86 & 10.19 & 34.13 & 20.40 & 0.13 & 81.84 & 5.86 & 169.4 \\
\hline Sec11 & 0.46 & 0.09 & 0.01 & 0.01 & 0.02 & 0.02 & 0.07 & 0.02 & 0.17 & 0.08 & 29.89 & 0.01 & 2.00 & 0.53 & 33.4 \\
\hline Sec12 & 18.47 & 0.49 & 0.17 & 0.12 & 1.05 & 0.83 & 2.04 & 7.53 & 16.67 & 2.04 & 23.39 & 21.65 & 54.60 & 6.54 & 155.6 \\
\hline Sec13 & 30.71 & 0.22 & 0.51 & 0.11 & 0.74 & 1.35 & 1.76 & 0.34 & 2.89 & 2.30 & 24.01 & 0.38 & 361.50 & 14.97 & 441.8 \\
\hline Sec14 & 157.90 & 0.87 & 5.57 & 0.60 & 4.47 & 2.29 & 12.16 & 2.60 & 16.35 & 12.01 & 142.81 & 2.83 & 274.35 & 265.62 & 900.4 \\
\hline DWUP & 1140 & 6.5 & 31.1 & 5.9 & 9.2 & 12.7 & 38.1 & 15.5 & 63.5 & 51.4 & 276.1 & 25.1 & 826.7 & 298.2 & 2800 \\
\hline
\end{tabular}




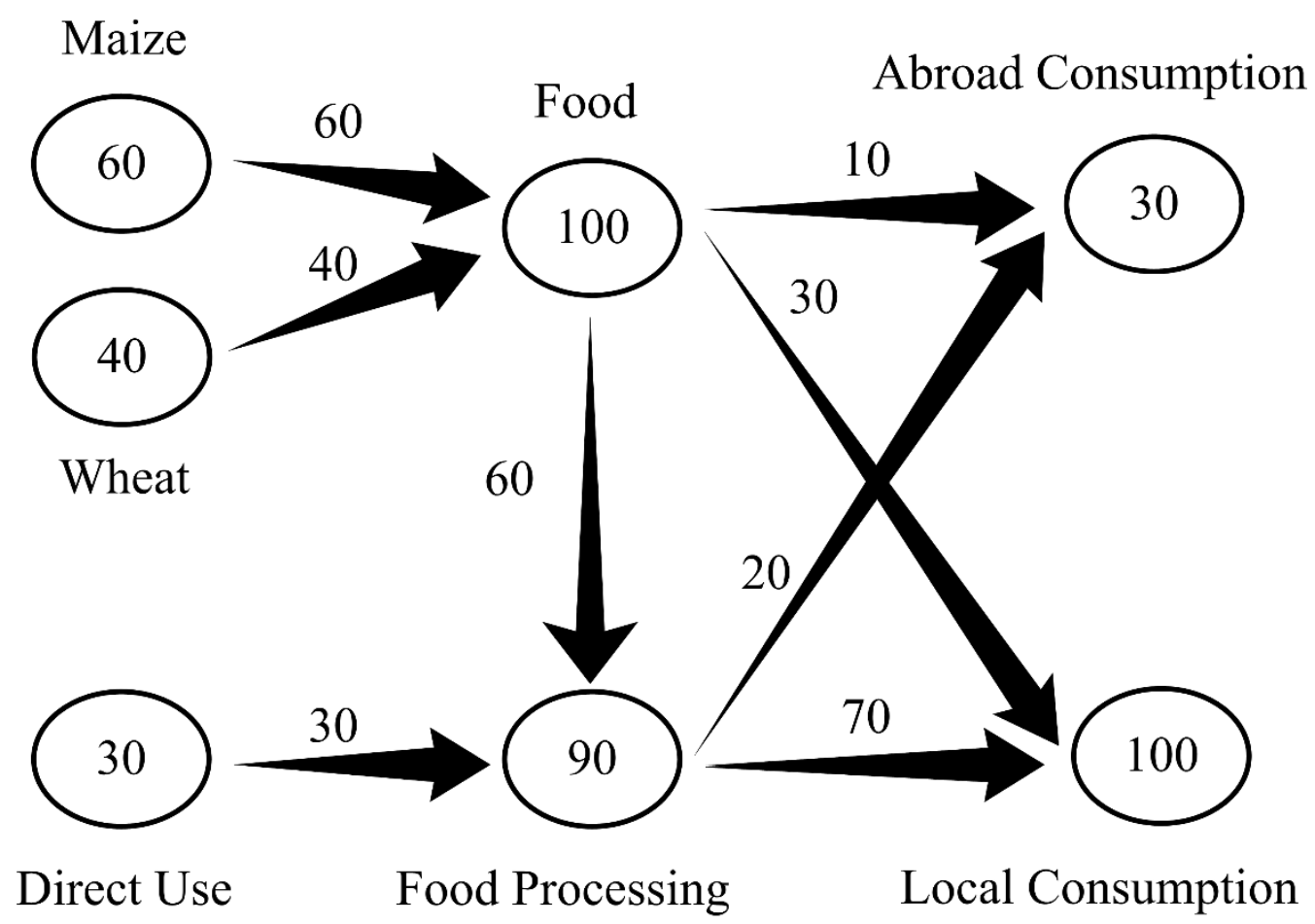

Fig. 1 A simple framework of virtual water flow in the supply chain of products 


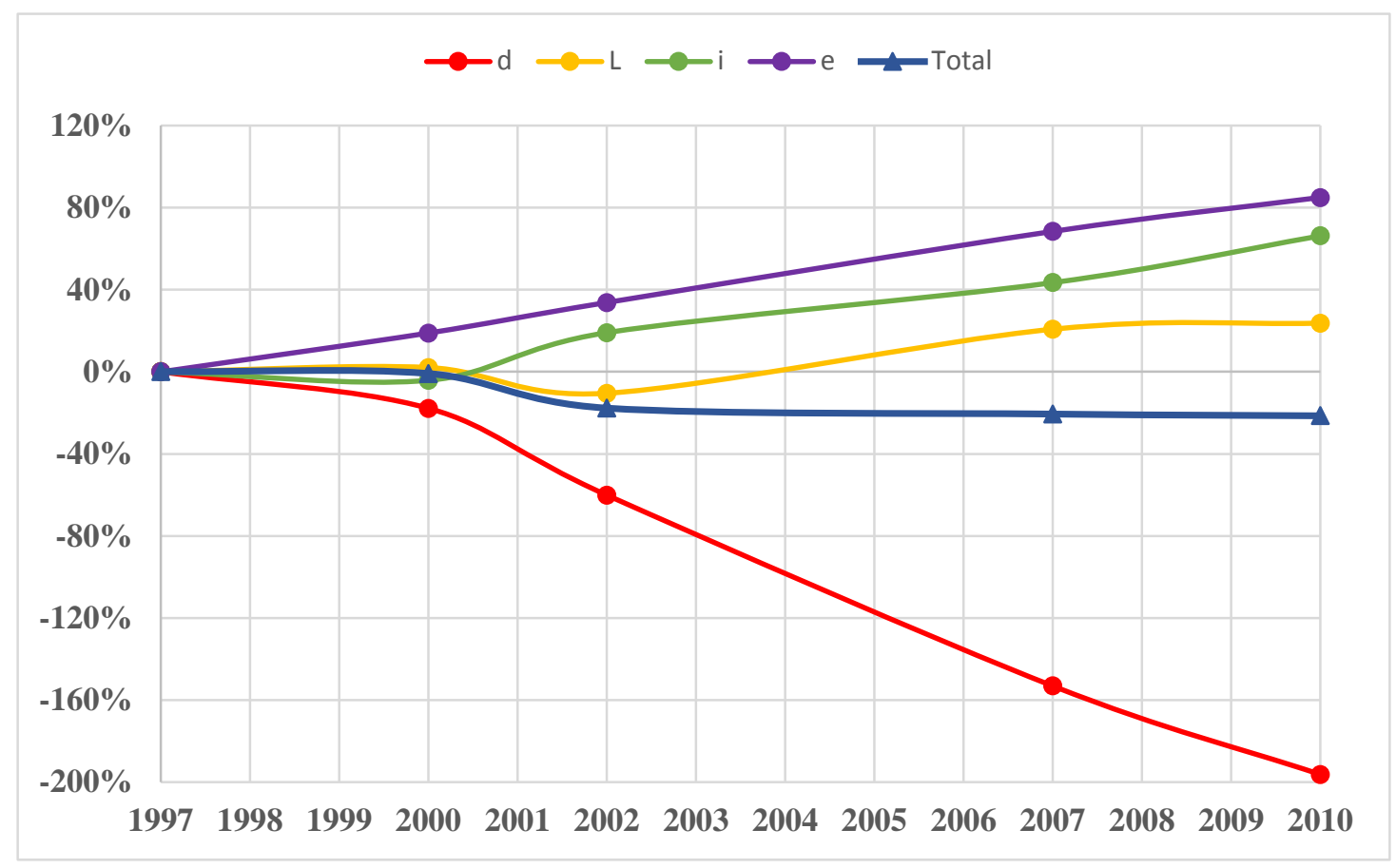

Fig 2. Structural decomposition analysis of Beijing's IWUP from 1997 to 2010.

The blue line shows the percentage change in IWUP from 1997 to 2010. Other colored lines represent the contribution to change from direct water use intensity (red), production structure adjustment (orange), internal final demand (green), and export (purple). 